\title{
Pathology and pathogenesis of retinal detachment
}

NG Ghazi and WR Green

\section{Ther \\ (II) Mechanisms of normal attachment of NSR to RPE}

\begin{abstract}
Retinal detachment, separation of the neurosensory retina from the underlying retinal pigment epithelium, is a sight threatening condition that is considered one of the few ocular emergencies. The literature is enormously rich in studies that focused on different aspects of this disease process. Yet certain aspects remain largely unanswered. We briefly review major aspects of retinal detachment and discuss various important contributions in this field, focussing mainly on the pathogenesis of and predisposing factors to retinal detachment, and on the pathologic changes that occur following its development and following various surgical procedures currently used in its
\end{abstract} management.

Eye (2002) 16, 411-421. doi:10.1038/

sj.eye. 6700197

Keywords: exudative; mechanisms; neurosensory retina; pathogenesis; pathology; posterior vitreous detachment

\section{(I) Definition}

Retinal detachment is the separation of the neurosensory retina (NSR) from the underlying retinal pigment epithelium (RPE). These two layers are derived from neuroectoderm that lines the optic vesicle during embryogenesis. As the optic vesicle invaginates to form the optic cup, the two layers come in apposition. The inner layer differentiates into the NSR and the outer into RPE. No real anatomic junctions form between the cells of the two layers. ${ }^{1}$ Therefore, the forces of attachment of the NSR to RPE are weak and once overwhelmed, a retinal detachment occurs that reestablishes the potential space between the two layers.
The forces of adhesion between the two layers can be divided into mechanical and metabolic. ${ }^{2}$ Mechanical factors in turn are divided into those outside and those inside the subretinal space (SRS)

Mechanical forces outside the SRS include fluid pressures and vitreous. Fluid exits the eye through the trabecular meshwork; however, a small proportion tends to exit from the vitreous to the choroid by virtue of the intraocular and choroidal oncotic pressures. ${ }^{3,4}$ Because the retina and RPE substantially resist fluid transport, the outward vector of fluid movement tends to push the retina against the RPE. ${ }^{5,6}$ Likewise, a drug that increases the vitreous oncotic pressure tends to withdraw fluid into the vitreous from the choroid through the retina. This inward vector of fluid movement could lead to retinal separation from the RPE because of retinal resistance to flow. ${ }^{7,8}$

Formed vitreous acts as a seal to retinal breaks and indirectly aids in preventing retinal detachment and maintaining adhesion between the retina and RPE. ${ }^{9}$ Whether the vitreous plays a direct role in retinal adhesion is yet to be determined although some studies suggest that the physical structure of the vitreous might be of importance in maintaining retinal apposition. ${ }^{9,10}$

Mechanical forces inside the SRS include the matrix material between the NSR and RPE and the interdigitations between the RPE microvilli and the photoreceptors.

A matrix is present in-between

photoreceptor outer segments and is called the interphotoreceptor matrix (IPM). It is predominantly composed of glycosaminoglycans. ${ }^{11}$ This matrix may act as a glue ${ }^{12}$ binding the NSR and RPE. The IPM also has structural components that remain attached to both the RPE and the cones if the NSR was peeled off the RPE. ${ }^{13-16}$ Cell adhesion molecules or receptors may be
The W Richard Green Eye Pathology Laboratory Wilmer Institute Department of Pathology The Johns Hopkins Medical Institutions

Baltimore

Maryland, USA

Correspondence:

WR Green, MD

Eye Pathology Laboratory

Maumenee 427

The Johns Hopkins Hospital 600 North Wolfe Street Baltimore

MD 21287-9248

USA

Tel: 410 955-3455

Fax: 410 614-3457

E-mail:wrgreen@jhmi.edu 
involved in this interaction between the matrix and the cellular membranes. ${ }^{16-18}$ Factors that affect the physicochemical properties of the IPM and enzymes that degrade some of its components weaken retinal adhesion. ${ }^{19,20}$

The mechanism by which interdigitations of RPE apical villous processes and photoreceptor outer segments contribute to retinal adhesion is not yet clear. However, three mechanisms have been proposed. These include the continuous process of phagocytosis of photoreceptor outer segments by RPE cells during which the two cells are intimately connected, ${ }^{2}$ the frictional forces that result from the interdigitations, ${ }^{2}$ and the possible presence of electrostatic interaction between the cell membranes. ${ }^{21}$

Metabolic factors that affect retinal adhesion include oxygenation. Retinal adhesion decreases tremendously postmortem ${ }^{20,22}$ and is restored with oxygenation. ${ }^{23}$ This can be either due to the effect of released RPE lysosomal enzyme on IPM ${ }^{24}$ or due to the effect of ischemia on active RPE fluid transport. ${ }^{2}$ The importance of metabolic factors in retinal adhesions is also inferred from the effect of many drugs that interfere with the $\mathrm{pH}$ and $\mathrm{RPE}$ fluid transport activity. ${ }^{2}$

\section{(III) Types and pathogenetic mechanisms of retinal detachment}

A retinal detachment occurs when the forces of adhesion between the NSR and the RPE are overwhelmed. This can occur by different mechanisms. Regardless of the mechanism, all types of retinal detachment have one characteristic in common, the accumulation of subretinal fluid. There are four major types of retinal detachment: rhegmatogenous, traction, exudative or serous, and combined traction-

rhegmatogenous.

Rhegmatogenous retinal detachment (RRD) is characterized by the presence of a full thickness retinal break as the prefix rhegma, which means rent in Greek, implies. This break is held open by vitreoretinal traction that allows accumulation of liquefied vitreous under the retina separating it from the RPE. Therefore, the precursors to this type of retinal detachment are liquefied vitreous, tractional forces that can produce and maintain a retinal break, and a break through which fluid gains access to the subretinal space. ${ }^{25}$ Even if a full thickness break is present in the retina, a retinal detachment will not occur if the vitreous is not at least partially liquefied and if the necessary traction is not present. ${ }^{26}$ Vitreous syneresis, which culminates in posterior vitreous detachment (PVD), can produce all three precursors of RRD. ${ }^{27}$ This is why in most instances an RRD is preceded by a PVD. With rotational eye movements, the detached vitreous moves within the vitreous cavity. Tractional forces are transmitted with these movements to the areas of persistent vitreous attachment. If these forces and the forces of vitreous attachment at these areas are strong enough, the retina tears. As the process of vitreous detachment progresses and the vitreous remains adherent to the flap of the break a horseshoe tear will result. On the other hand, if the vitreous traction is strong enough to cause avulsion of the retinal flap at its base, an operculated tear results and the traction resolves. Once a break occurs, ocular saccades cause fluid vitreous movement that may force fluid into the subretinal space dissecting the NSR off the RPE especially if the break is held open by vitreous traction (horseshoe tear). ${ }^{33,34}$ Hence an RRD ensues.

Depending on the location of this pathology, RRD can be classified into equatorial, oral and macular. ${ }^{35-38}$ Equatorial RRD occurs in cases of myopia, lattice degeneration, horseshoe tears and round retinal holes. Oral RRD is most commonly seen in cases of aphakia, pseudophakia, dialysis in the young, ${ }^{39-41}$ traumatic dialysis, and giant retinal tears. ${ }^{42}$ Macular type is seen in high myopia, traumatic holes and idiopathic macular holes.

Other less frequent causes of RRD include various forms of necrotizing retinitis, like toxoplasmosis, ${ }^{43}$ cytomegalovirus infection, ${ }^{44,45}$ and acute retinal necrosis syndrome ${ }^{46}$ all of which increase the chance of developing full thickness retinal tears.

Traction retinal detachment (TRD) occurs when the retina is pulled off the RPE by tractional forces in the absence of retinal tears. These forces can be transmitted to the retina either through tractional bands or membranes that are contiguous with the retina, or through vitreous strands bridging the retina to tractional bands, or purely through vitreous bands as in cases of vitreous loss and vitreous incarceration in surgical wounds. This type of retinal detachment, however, is most common in proliferative retinal and vitreoretinal diseases, like proliferative diabetic retinopathy, sickle cell retinopathy, retinopathy of prematurity and proliferative vitreoretinopathy; and following penetrating trauma, ${ }^{47-50}$ where contractile fibrous and/or fibrovascular tissue forms within the vitreous cavity and/or periretinally and leads to TRD.

Combined traction-rhegmatogenous retinal detachment (TRRD), as the name implies, is the result of a combination of a retinal break and retinal traction. The retinal break, which is mostly located near a fibrous or fibrovascular proliferation, is usually secondary to traction that is the major component of retinal detachment in these cases. ${ }^{25}$ This form of retinal 
detachment, like TRD, is most common in proliferative retinal and vitreoretinal diseases.

Exudative, transudative or serous retinal detachment (SRD) is characterized by fluid accumulation in the subretinal space in the absence of retinal breaks or traction. The source of the fluid is the vessels of the retina, or the choroid, or both. This can occur in a variety of vascular, inflammatory or neoplastic diseases of the retina, RPE, and choroid ${ }^{51}$ in which fluid leaks outside the vessels and accumulates under the retina. As long as the RPE is able to pump the leaking fluid into the choroidal circulation, no fluid accumulates in the subretinal space and no retinal detachment occurs. However, if the process continues and the normal RPE pump activity becomes overwhelmed, or if the RPE activity decreases because of RPE loss or decreased metabolic supply (eg ischemia), then fluid starts to accumulate and a retinal detachment occurs. ${ }^{52}$ This type of retinal detachment can be also due to accumulation of blood in the subretinal space (hemorrhagic retinal detachment). Inflammatory diseases that can lead to SRD include posterior scleritis, sympathetic ophthalmia, Harada disease, pars planitis, and collagen vascular diseases. Vascular diseases include malignant hypertension, toxemia of pregnancy, retinal vein occlusion, Coats disease, retinal angiomatous diseases, and different forms of choroidal neovascularization including polypoidal choroidal vasculopathy. ${ }^{53,54}$ Choroidal tumors that may be associated with SRD include some nevi, melanoma, hemangioma, lymphoma, and metastatic tumors. Other conditions that are associated with SRD include central serous chorioretinopathy, familial exudative vitreoretinopathy, Norrie disease, uveal effusion syndrome, nanophthalmia, and optic nerve head pits and colobomas are still somewhat enigmatic and are not classified under any of the three disease processes that lead to SRD discussed above. Also SRD can be iatrogenic following retinal detachment surgery ${ }^{55}$ and laser photocoagulation.

\section{(IV) Predisposing factors to retinal detachment}

Factors predisposing to TRD and SRD are the disease entities associated with them as discussed above. However, factors predisposing to RRD are less obvious, more difficult to diagnose and, when they exist, the indications for prophylactic treatment are sometimes controversial. These include vitreoretinal adhesions in association with PVD; local ocular diseases such as retinoschisis and myopia; cataract surgery; trauma; and most of the hyaloideoretinopathies the prototype of which is the Stickler syndrome. Most of these entities predispose to
RRD because of the high incidence of associated vitreous detachment and retinal breaks.

As discussed earlier RRD develops in association with retinal breaks that develop at physiologic or pathologic sites of firm vitreoretinal adherence during PVD. The incidence of retinal tears varies from 0.59 to $27 \%$ according to different studies, ${ }^{28,35}$ as does the incidence of retinal detachment in patients with retinal tears. Clearly, not every retinal tear leads to retinal detachment ${ }^{56,57}$ since the prevalence of retinal tears was found to be 83 times that of retinal detachment. ${ }^{56}$ Therefore, prophylactic treatment of retinal tears should be selective and is recommended for symptomatic tears ${ }^{56}$ and horseshoe tears with persistent vitreous traction. ${ }^{58}$

In addition to the normal sites of strong attachment between the vitreous and retina, several peripheral retinal lesions are characterized by anomalous vitreoretinal adhesion and hence predispose to full thickness retinal breaks when the vitreous detaches and pulls on the retina at these sites. Anomalous vitreoretinal adhesion occurs at enclosed and partially enclosed ora bays, ${ }^{29}$ meridional folds and complexes, retinal tufts, ${ }^{30,36}$ and lattice degeneration. ${ }^{31,37}$

Ora bays represent a posterior indentation in the retina. This indentation can be completely (enclosed ora bay) or incompletely (partially enclosed ora bay) surrounded by retinal tissue. In a study of 1000 autopsy eyes, Spencer et $a l^{59}$ found that retinal tears were associated with $16.7 \%$ of either type of ora bays; however, retinal tears associated with ora bays were present in only $0.5 \%$ of all eyes.

Meridional folds are elevated radial retinal folds that are aligned with a dentate process or an ora bay. The association of a retinal fold, a dentate process and a ciliary process in alignment is a meridional complex. Conflicting data as to the incidence of retinal tears associated with these lesions is present in the literature. ${ }^{60,61}$

There are three types of retinal tufts: non-cystic, cystic, and zonular. ${ }^{30,36,62,63}$ These are projections of retinal fibroglial tissue into the vitreous and are usually located in the vitreous base nasally or inferiorly. Noncystic tufts are not associated with cystic degeneration of the retina, nor are they associated with retinal tears or detachment. Cystic retinal tufts are cystic projections and are sometimes associated with localized cystic degeneration of the retina and condensed vitreous strands at the apex. ${ }^{62}$ In one study, Byer $^{64}$ found that $6.5 \%$ of retinal detachments are associated with holes that develop with PVD at the areas of cystic tufts. He also noted that prophylactic therapy of these lesions is not necessary because the risk of developing retinal detachment secondary to 
cystic tufts is less than $1 \%$. Zonular tufts are projections of neuroglial tissue or embryonal-like epithelium that extend anteriorly from the peripheral retina at an acute angle where they become continuous with a lens zonule. The zonular tractional tufts are a means by which direct traction on the retina can occur from manipulation of the lens. The retina at these sites often has cystic changes. Foos ${ }^{65}$ classified associated retinal changes into trophic and tractional. The former include partial and full thickness holes; the latter include rupture of the tuft and full thickness breaks $(2.2 \%)$. Generally these lesions are not associated with an increased risk of retinal detachment except if the breaks associated with them are extrabasal, particularly following cataract extraction. ${ }^{66}$

Retinal pits (lamellar retinal breaks) do not lead to retinal detachment but are a sign of posterior vitreous detachment and retinal traction. ${ }^{32,38,67}$

The strong vitreoretinal adhesions present at the margins of lattice degeneration are well documented. Lattice lesions can vary in shape, appearance, location and pigmentation. They are most commonly preequatorial, parallel to the ora serrata, and located in the vertical meridians. ${ }^{31,37}$ Lattice degeneration also may occur posterior to the equator in a radial perivascular pattern. ${ }^{57,68}$ More than ten histopathologic features of lattice degeneration have been identified ${ }^{58-}$ 60,68-71 including retinal thinning and degeneration with atrophic hole formation, liquefaction of the overlying vitreous, and firm adhesion of the vitreous at the margins of the lesion with glial and RPE cell proliferation. ${ }^{31,37}$ Traction retinal breaks may occur at the posterior margin of the lattice lesion during PVD due to firm vitreoretinal adhesion. However, the incidence of traction breaks directly involving a lattice lesion is small. ${ }^{69,72}$ Tears are more likely to occur in juxtabasal and extrabasal lesions. ${ }^{73}$ Atrophic holes are more common. Straatsma et al ${ }^{69}$ found that the histologic incidence of atrophic holes and traction retinal breaks in lattice lesions is $18.2 \%$ and $1.4 \%$ respectively. In his clinical studies, Byer ${ }^{26,71}$ calculated the incidence of retinal detachment from traction retinal breaks and atrophic holes associated with lattice degeneration to be $0.3-0.5 \%$ only. Retinal breaks associated with radial perivascular lattice are usually larger and more posterior and hence might lead to retinal detachments that are difficult to treat. The indications for prophylactic treatment of lattice lesions are influenced by the clinician's evaluation, experience and bias. Most authors agree that symptomatic tears, history of retinal detachment in the fellow eye, high myopia, aphakia or planned aphakia are indications for prophylactic therapy. ${ }^{71,74,75}$

RRD in retinoschisis occurs when holes are present in both the inner and outer layers of the retina involved by schisis. In these cases fluid passes into the subretinal space through the inner and outer holes. A hole occurring in only one of the retinal layers is not enough to produce significant retinal detachment although outer retinal holes might lead to localized detachment. Retinoschisis was observed in $2.5 \%$ of patients with RRD. ${ }^{76}$

Myopia is a definite risk factor for retinal detachment and the risk increases with higher degrees of myopia. ${ }^{77,78}$ PVD occurs early, ${ }^{79,80}$ lattice degeneration is more common ${ }^{81}$ and the retina is thinner in myopic patients than in emmetropes, and this makes retinal breaks and detachment a more frequent occurrence and they are often bilateral. ${ }^{77,82,83}$ Prophylactic treatment is indicated for horseshoe-tears, symptomatic tears, tears with surrounding retinal fluid, in patients with history of retinal detachment, and probably in patients undergoing cataract extraction. However, this is a controversial issue and some authors advise to treat any break in patients with more than 4 diopters of myopia. ${ }^{83-85}$

Macular holes are also seen in cases of high myopia. The retinal detachment complicating these holes is usually limited to the posterior pole within the temporal vascular arcades and may be nonprogressive. ${ }^{86}$ Treatment of these cases is still controversial. ${ }^{87,88}$

The crystalline lens and its posterior capsule constitute a stabilizing factor on the vitreous body. The vitreous movements during ocular saccades are transmitted from the outer layers of the vitreous towards the center. The same thing happens at the conclusion of a saccade. These accelerational and decelerational movements of the vitreous are dampened by the firm vitreous adhesions to the retina and the posterior convexity of the lens. The latter 'exerts a grip or mechanical hold on the vitreous body'. ${ }^{27}$ With removal of the lens after cataract surgery this 'grip' is lost and the torsional effects at physiologic and pathologic sites of firm vitreoretinal adhesions are accentuated. ${ }^{89,90}$ Another effect of lens extraction on the vitreous is at the molecular level. Vitreous hyaluronan concentration decreases following cataract extraction and this is much more prominent following ICCE. ${ }^{91,92}$ The posterior capsule, when preserved, is thought to act as a barrier to diffusion. The decrease in hyaluronan concentration accelerates the process of syneresis and decreases the shock-absorbing property of the vitreous body, thus leading to an increase in the torsional forces transmitted to areas of vitreoretinal adhesions. These mechanical and biochemical alterations that occur following cataract extraction increase the incidence of PVD $^{91,93}$ and retinal tears and 
detachment. ${ }^{94}$ In one large study, ${ }^{94}$ the risk of retinal detachment following cataract extraction was 7.5 times that of a control group even 6 years after surgery. The risk of retinal detachment following extracapsular cataract extraction with posterior chamber intraocular lens varies according to different series but is about $1.4 \% .{ }^{95}$ The presence of an intact capsule appears to decrease the risk of retinal detachment following cataract surgery. ${ }^{96}$

Vitreous incarceration in a cataract wound is another factor contributing to vitreoretinal traction and retinal detachment; however, in such cases the detachment may be tractional rather than rhegmatogenous. ${ }^{97}$

About $15 \%$ of all retinal detachments are traumatic and they are much more common in young individuals. ${ }^{98}$ Blunt trauma, with and without rupture of the globe, and penetrating trauma can cause retinal detachments. RRD is more important in the setting of a closed-globe blunt trauma or contusion. Blunt trauma represents about $70-85 \%$ of all traumatic retinal detachments. ${ }^{99-101}$ In the case of blunt trauma with rupture and penetrating trauma, TRD secondary to fibrous ingrowth and intraocular proliferation is more prominent. ${ }^{47-49,102-107}$

Closed-globe blunt trauma, or ocular contusion, can, directly or indirectly (contrecoup), cause several vitreoretinal changes including dialysis at the anterior or posterior border of the vitreous base; avulsion of the vitreous base; horseshoe-shaped tear at the posterior margin of the vitreous base, at the posterior margin of a meridional fold, or at the equator; operculated tear; and macular holes. ${ }^{108,109}$ About $60 \%$ of traumatic retinal breaks were located at the ora, whereas $60 \%$ of nontraumatic tears were equatorial. ${ }^{109}$ The frequent occurrence of retinal breaks, the most important of which being retinal dialysis, in ocular contusion injury has been repeatedly emphasized. ${ }^{110-113}$ Studies performed on animal models of ocular blunt trauma ${ }^{114,115}$ indicated that the initiating factor in the pathogenesis of retinal detachment is the anteroposterior (AP) compression of the globe during impact that leads to a compensatory lengthening of the horizontal diameter. This AP reduction can be as significant as $59 \%$ and, at the termination of impact or collision, the globe re-expands in the AP direction with an 'overshoot' up to $112 \%$ its original length. ${ }^{115}$ During this process of AP reduction and overshoot marked traction at the vitreous base and other areas of physiologic or pathologic vitreoretinal adhesion occurs.

The occurrence of retinal breaks following ocular contusion is not sufficient to induce retinal detachment because the vitreous in such young patients is intact and provides a tamponade or sealing effect on retinal breaks. Vitreous liquefaction has to occur before detachment develops. Traumatic vitreous syneresis may occur following trauma, at which time fluid seeps into the subretinal space through the break leading to retinal detachment. ${ }^{116}$

Nine percent of all macular holes develop following blunt trauma ${ }^{117}$ and these can lead to retinal

detachment. Several mechanisms ${ }^{118}$ have been proposed for the development of these holes including post-contusion necrosis and vitreoretinal traction by a contrecoup effect. The results of surgery for traumatic macular hole closure are favorable. ${ }^{119,120}$

The hyaloideoretinopathies include a number of diseases with much overlap in the clinical and sometimes genetic characteristics. Most of these diseases share common dystrophic retinal and vitreal changes; however, they sometimes differ by the predominance of one of these changes. ${ }^{121}$ The characteristic ocular features as far as RRD is concerned include vitreous liquefaction (optically empty vitreous) and retinal break formation. Discussion of this group of diseases is beyond the scope of this paper.

\section{(V) Pathologic changes following retinal detachment}

When the retina separates from the RPE secondary to retinal detachment of any type, the outer retina becomes ischemic due to loss of its blood supply from the choroid. The biochemical interplay between the RPE and the retinal photoreceptors is affected. The earliest light microscopic manifestations include accumulation of subretinal fluid with loss of photoreceptor outer segments, and if the process persists the entire photoreceptor cell layer becomes atrophic. ${ }^{35,122,123}$ Apoptosis appears to play an important role in the time-dependent photoreceptor cell decay that occurs following retinal detachment. ${ }^{124,125}$ Machemer and coworkers ${ }^{126,127}$ showed that degeneration of the photoreceptor outer segments occurs following experimental detachment in the monkey; however, they readily regenerate with surgical reattachment, more so for the rods than cones. Nonetheless, clinical experience is that once the macula is detached, vision does not return to what it was before detachment even following anatomic surgical success. This indicates that some changes persist. In one experiment in monkeys, ${ }^{123}$ persistent outer segment abnormalities were observed in 'otherwise well regenerated areas' following retinal reattachment. These included abnormalities in the orientation and alignment of the outer segments, location of the cilium, and disk alignment.

In cases of chronic detachment, more prominent 
changes occur including cystic and macrocystic retinal degeneration, retinal thinning, RPE alterations, demarcation lines, large drusen, choroidal neovascularization at the ora serrata ${ }^{128}$ and iris neovascularization secondary to angiogenic factor elaboration by the ischemic detached retina. In some cases photoreceptor outer segments were observed in the aqueous humor of patients with retinal detachment, particularly atopic patients. ${ }^{129}$

\section{(VI) Pathologic changes following surgery for retinal detachment}

Cryopexy, laser photocoagulation, scleral buckling, and vitrectomy, with and without the use of vitreous substitutes, have all been used, individually or in combination, in the treatment of retinal detachment. Studies on the histologic changes that occur following these procedures have been previously reported.

Cryopexy leads to formation of intracellular ice crystals. ${ }^{130}$ Diffuse atrophy of the RPE and choroidal pigment is characteristic of the resultant lesions. In addition, damage to smaller vessels, accumulation of pigmented macrophages in areas of RPE atrophy, proliferation of adjacent RPE, loss of the photoreceptor cell layer and glial cell proliferation in the outer retina with formation of chorioretinal adhesions occur. ${ }^{131}$ Dispersion of RPE cells into the vitreous cavity with subsequent proliferative vitreoretinopathy might complicate cryotherapy. ${ }^{132}$

Different types of lasers have been used in the treatment of retinal breaks and detachment, and they all work by the same mechanism. Light energy is predominantly absorbed by the RPE and transformed into heat that gets transmitted to adjacent tissues. This causes variable degrees of destruction in the RPE, photoreceptors and choriocapillaries, and eventually leads to chorioretinal scarring and adhesion. These histologic changes that occur following laser therapy are comparable regardless of the type of laser used. ${ }^{133-136}$

The histopathologic features following retinal detachment surgery by scleral buckling have been previously reviewed. ${ }^{137-139}$ Twenty nine percent of the 204 eyes in an early series studied by Boniuk and Zimmerman ${ }^{126,139}$ had clinically unsuspected tumors, 14 eyes $(6.9 \%)$ had no evidence of tumor though they were enucleated because of the suspicion of an ocular tumor, $23 \%$ had anterior segment necrosis, and glaucoma was present in most of the cases. Lensinduced endophthalmitis, granulomatous and sympathetic uveitis, keratitis, reaction to sutures and implants, and infection and internal erosion of buckle elements were other less conspicuous findings. In the study of 49 eyes, following scleral buckling procedure, Wilson and Green ${ }^{137}$ found epiretinal membranes in $75.5 \%$, macular pucker secondary to epiretinal membranes in $30.6 \%$, photoreceptor atrophy in $26.5 \%$, element in-erosion in $21.7 \%$, cystoid macular edema and ciliochoroidal effusion each in $10.2 \%$, anterior segment necrosis in only $8.2 \%$ compared to $23 \%$ in the study of Boniuk and Zimmerman, and choroidal neovessels in $6.1 \%$ of the cases. One eye with cystoid macular edema also had an inner lamellar macular hole. The authors noted that photoreceptor cell atrophy could explain the fact that visual recovery is limited following successful reattachment of macula-off retinal detachments. This appears to be dependent on the duration of retinal detachment prior to reattachment. ${ }^{124,140,141}$

$\mathrm{D}^{\prime}$ Hermies et $a l^{142}$ studied 60 encapsulations of scleral buckling materials from patients who had undergone scleral buckling procedures for retinal detachment using either a silicone or a hydrogel element. The capsules were composed of a fibrous matrix with fibroblasts and inflammatory cells. Sixteen of the 37 hydrogel capsule specimens contained foci of giant cell foreign body reaction around hydrogel fragments. None of the silicone capsule specimens had giant cell reaction or silicone fragments.

Barr ${ }^{138}$ studied 15 enucleated eyes that previously had RRD successfully reattached with scleral buckling. Sixty percent of the eyes had epiretinal membrane formation and $26 \%$ had cystoid macular edema. Twenty six percent of the reattached retinas had significant atrophy of the outer retinal layers. Ten eyes had reduced postoperative vision. Outer retinal atrophy and CME could account for five cases but the other five eyes had no histopathologic explanation of their reduced postoperative acuity.

The changes that occur following pars plana vitrectomy (PPV), with and without tamponade or vitreous substitutes, for retinal detachment have not been described in a large series yet. However, findings in individual case reports have been described.

Yamana et al $^{122}$ assessed the effect of gas tamponade on the process of experimental retinal hole closure in rabbits. Ophthalmoscopically, the holes closed and the detached retina around holes reattached by 7 days in the group of eyes that received sulfur hexafluoride gas tamponade after hole induction. The retinal holes remained open at the end of the observation period in the eyes without gas tamponade. Histologic and immunohistochemical analysis disclosed the holes to be filled with cytokeratin-and-glial fibrillary acidic protein-positive cells.

In a clinical and experimental study Krieger ${ }^{143}$ observed that the pars plana sclerotomy incisions heal 
in a spectrum from localized scarring to uncontrolled fibrovascular proliferation with untoward clinical effects. In another study ${ }^{144}$ the histologic changes of the pars plana incisions in four eyes during PPV included fibrovascular ingrowth in four eyes and fibrous tissue ingrowth in one eye.

Mietz et al ${ }^{145}$ described the light and ultrastructural findings in two epiretinal membranes that were obtained by PPV from two eyes that were previously operated by PPV and silicone oil with daunomycin. The membranes were composed of new collagen, fibrocytes and macrophages. Only one specimen had RPE and fibrous astrocytes. Numerous silicone oil vacuoles were observed within some macrophages and RPE cells as well as extracellularly in both membranes. In another study ${ }^{146}$ of two enucleated eyes and a subconjunctival specimen from a third case, silicone vacuoles were observed in the anterior chamber angle, retina, choroid, beneath the RPE, and in fibrous tissue surrounding lens debris in one eye. Silicone oil had been present for at least 2 years prior to enucleation in that eye. In the other eye and the third case, specimens were obtained within 3 months of silicone oil injection. Silicone oil cavities were observed within epiretinal proliferation in the former, and in subconjunctival fibrovascular tissue in the latter. Eller et $a l^{147}$ found evidence of silicone oil within the ventricular system on computed tomography and magnetic resonance imaging in a patient who developed glaucoma secondary to silicone oil retinal tamponade. Brain imaging was done 15 months following silicone oil injection.

The histopathologic changes that occur with shortterm use of high-density vitreous substitutes (particularly fluorosilicone, silicone-fluorosilicone copolymer oil and perfluorocarbon liquids that are usually used in difficult cases of retinal detachment and to unfold giant retinal tears) have been reviewed. In one light and electron microscopic study of rabbit eyes, ${ }^{148}$ the experimental retinas were similar to controls 2 weeks following injection of fluorosilicone in the vitreous cavity. However, 4 weeks following injection the outer plexiform layer disappeared in all the study eyes and by 8 weeks some photoreceptor cell nuclei migrated into the photoreceptor layer. These changes were limited to the inferior half of the retina and the superior retina was similar to controls in all cases. The authors did not find preretinal proliferation or foam cells.

In a clinicopathologic study ${ }^{149}$ of five eyes with retained perfluoro-n-octane (PFO) liquid after retinal detachment surgery, specimens were obtained at the time of further surgery. All eyes had macroscopic 'white flake-like material' on intraocular structures that was observed either pre- or intra-operatively. Histologic and ultrastructural analysis disclosed chronic inflammatory cells with macrophages containing intracellular vacuoles. In two specimens it was difficult to tell whether the vacuoles contained silicone oil or PFO because both substances were used at the time of initial surgery. Energy dispersive spectroscopy was performed and the material within the vacuoles was identified as PFO because of the absence of a 'silicone spike'.

Periretinal proliferations, including epiretinal and retroretinal membranes and proliferative vitreoretinopathy (PVR), have become more commonly recognized complications of retinal breaks, detachment, and surgery for retinal detachment. Discussion of these complications is beyond the scope of this paper. The cell types that contribute to the membranes noted in these conditions include fibrous astrocytes, retinal pigment epithelial cells, fibrocytes, that may or may not have myoblastic features, and Mueller cells. The most common cell type observed in secondary epiretinal membranes is the fibrous astrocyte, while RPE cells predominate in PVR. ${ }^{31}$

\section{Acknowledgements}

Supported in part by the Independent Order of Odd Fellows, Winston-Salem, North Carolina.

\section{References}

1 Steinberg RH, Wood I. Pigment epithelial cell ensheathment of cone outer segments in the retina of the domestic cat. Proc R Soc Lond 1974; B.187: 461-478.

2 Marmor MF. Mechanisms of normal retinal adhesion. In: Ryan SJ, Wilkinson CP (eds). Retina. Mosby: St Louis, 2001, pp 1849-1869.

3 Maurice DM. Flow of water between aqueous and vitreous compartments in the rabbit eye. Am J Physiol 1987; 252: F104-108.

4 Bill A. Some aspects of tissue fluid dynamics in the eye. In: Cant JS (ed). Vision and Circulation. Mosby: St Louis, 1976, pp 333-338.

5 Fatt I, Shantianath K. Flow conductivity of retina and its role in retinal adhesion. Exp Eye Res 1971; 12 :218-226.

6 Tsuboi S. Measurement of the volume flow and hydraulic conductivity across the isolated dog retinal pigment epithelium. Invest Ophthalmol Vis Sci 1987; 28: 1776-1782.

7 Marmor MF. Retinal detachment from hyperosmotic intravitreal injection. Invest Ophthalmol Vis Sci 1979; 18: 1237-1244.

8 Marmor MF, Martin LJ, Tharpe S. Osmotically induced retinal detachment in the rabbit and primate. Invest Ophthalmol Vis Sci 1980; 19: 1016-1029.

9 Foulds WS. The vitreous in retinal detachment. Trans Ophthal Soc UK 1975; 95: 412-416.

10 Osterlin S. On the molecular biology of the vitreous in the phakic eye. Acta Ophthalmol 1977; 55: 353-361. 
11 Porrello K, La Vail MM. Histochemical demonstration of spatial heterogeneity in the interphotoreceptor matrix of the rat retina. Invest Ophthalmol Vis Sci 1986; 27: 15771586.

12 Berman ER. Mucopolysaccharides (glycosaminoglycans) of the retina: identification, distribution and possible biological role. Mod Probl Ophthal 1969; 8: 5-31.

13 Hageman GS, Marmor MF, Yao XY et al. The interphotoreceptor matrix mediates primate retinal adhesion. Arch Ophthalmol 1995; 113: 655-660.

14 Hageman GS, Johnson LV. The 'cone matrix sheath': structural, compositional and functional analysis. Invest Ophthalmol Vis Sci (suppl) 1988; 29: 108.

15 Hollyfield JG, Varner HH, Rayborn ME et al. Retinal attachment to the pigment epithelium. Linkage through an extracellular sheath surrounding cone photoreceptors. Retina 1989; 9: 59-68.

16 Hageman GS, Johnson LV. Structure, composition, and function of the retinal interphotoreceptor matrix. In: Osborne N, Chader J (eds). Progress in Retinal Research. Pergamon Press: Oxford, 1991, pp 207-250.

17 Kohno $\mathrm{T}$, Sorgente $\mathrm{N}$, Ishibashi $\mathrm{T}$ et al. Immunofluorescent studies of fibronectin and laminin in the human eye. Invest Ophthalmol Vis Sci 1987; 28: 506514.

18 Opas M, Kalnins VI. Distribution of spectrin and lectinbinding materials in surface lamina of RPE cells. Invest Ophthalmol Vis Sci 1985; 26: 621-627.

19 Yao XY, Hageman GS, Marmor MF. Retinal adhesiveness is weakened by enzymatic modification of the interphotoreceptor matrix in vivo. Invest Ophthalmol Vis Sci 1990; 31: 2051-2058.

20 Yao XY, Hageman GS, Marmor MF. Retinal adhesiveness in the monkey. Invest Ophthalmol Vis Sci 1994; 35: 744-748.

21 Gingell D, Fornes JA. Demonstration of intermolecular forces in cell adhesion using a new electrochemical technique. Nature 1975; 256: 210-211.

22 Marmor MF, Yao XY. The metabolic dependency of retinal adhesion in rabbit and primate. Arch Ophthalmol 1995; 113: 232-238.

23 Kim R, Yao XY, Marmor MF. Oxygen dependency of retinal adhesion. Invest Ophthalmol Vis Sci 1993; 34: 20742078.

24 Kain HL, Libondi T. Experimentelle netzhautablosunguntersuchungen zum pathomechanismus. Fortschr Ophthalmol 1986; 83: 590-596.

25 Bardbury MJ, Landers MB. Pathogenetic mechanisms of retinal detachment. In: Ryan SJ, Wilkinson CP (eds). Retina. Mosby: St Louis, 2001, pp 1987-1993.

26 Byer NE. Changes in prognosis of lattice degeneration of the retina. Tr Am Acad Ophth and Otol 1974; 78: 114-125.

27 Green WR, Sebag J. Vitreoretinal interface. In: Ryan SJ, Wilkinson CP (eds). Retina. Mosby: St Louis, 2001, 3rd edn, Vol 3, pp 1882-1960.

28 Green WR, Sebag J. Vitreoretinal interface. In: Ryan SJ, Wilkinson CP (eds). Retina. Mosby: St Louis, 2001, 3rd edn, Vol 3, pp 1915-1919.

29 Green WR, Sebag J. Vitreoretinal interface. In: Ryan SJ, Wilkinson CP (eds). Retina. Mosby: St Louis, 2001, 3rd edn, Vol 3, pp 1897-1906.

30 Green WR, Sebag J. Vitreoretinal interface. In: Ryan SJ, Wilkinson CP (eds). Retina. Mosby: St Louis, 2001, 3rd edn, Vol 3, pp 1899-1902.
31 Green WR, Sebag J. Vitreoretinal interface. In: Ryan SJ, Wilkinson CP (eds). Retina. Mosby: St Louis, 2001, 3rd edn, Vol 3, pp 1902-1906.

32 Green WR, Sebag J. Vitreoretinal interface. In: Ryan SJ, Wilkinson CP (eds). Retina. Mosby: St Louis, 2001, 3rd edn, Vol 3, p 1915.

33 Machemer R. The importance of fluid absorption, traction, intraocular currents, and chorioretinal scars in the theory of rhematogenous retinal detachments. Am J Ophthalmol. 1984; 98: 681-93.

34 Machemer R. Pathogenesis and therapy of traction detachment in various retinal vascular diseases. Am J Ophthalmol 1988; 105: 170-181.

35 Green WR. Retina. In: Spencer WH (ed). Ophthalmic Pathology: an Atlas and Textbook. WB Saunders: Philadelphia, 1996, 4th edn, Vol 2, pp 667-1313.

36 Green WR. Retina. In: Spencer WH (ed). Ophthalmic Pathology: an Atlas and Textbook. WB Saunders: Philadelphia, 1996, 4th edn, Vol 2, pp 948-954.

37 Green WR. Retina. In: Spencer WH (ed). Ophthalmic Pathology: an Atlas and Textbook. WB Saunders: Philadelphia, 1996, 4th edn, Vol 2, pp 926-938.

38 Green WR. Retina. In: Spencer WH (ed). Ophthalmic Pathology: an Atlas and Textbook. WB Saunders: Philadelphia, 1996, 4th edn, Vol 2, p 938.

39 Zion VM, Burton TC. Retinal dialysis. Arch Ophthalmol 1980; 98: 1971-1974.

40 Kinyoun JL, Knobloch WH. Idiopathic retinal dialysis. Retina 1984; 4: 9-14.

41 Smiddy WE, Green WR. Retinal dialysis: pathology and pathogenesis. Retina 1982; 2: 94-116.

42 Schepens CL. Retinal Diseases and Allied Diseases. WB Saunders: Philadelphia, 1983.

43 Hagler WS, Jarrett WH, Chang MC. Rhematogenous retinal detachment following chorioretinal inflammatory disease. Am J Ophthalmol 1978; 86: 373-379.

44 Broghton WL, Cupples HP, Parver LM. Bilateral retinal detachment following cytomegalovirus retinitis. Arch Ophthalmol 1978; 96: 618-619.

45 Meredith TA, Aaberg TM, Reeser FH. Rhematogenous retinal detachment complicating cytomegaloviris retinitis. Am J Ophthalmol 1979; 87: 793-796.

46 Duker JS, Blumenkranz MS. Diagnosis and management of the acute retinal necrosis (ARN) syndrome. Surv Ophthalmol 1991; 35: 327-343.

47 Cleary PE, Ryan SJ. Histology of wound, vitreous, and retina in experimental posterior penetrating eye injury in the rhesus monkey. Am J Ophthalmol 1979; 88: 221-231.

48 Cleary PE, Ryan SJ. Method of production and natural history of experimental posterior penetrating eye injury in the rhesus monkey. Am J Ophthalmol 1979; 88: 212220.

49 Gregor Z, Ryan SJ. Combined posterior contusion and penetrating injury in the pig eye. I. A natural history study. Br J Ophthalmol 1982; 66: 793-798.

50 Gregor Z, Ryan SJ. Combined posterior contusion and penetrating injury in the pig eye. II. Histological features. Br J Ophthalmol 1982; 66: 799-804.

51 Anand R, Tasman WS. Nonrhegmatogenous retinal detachment. In: Ryan SJ, Wilkinson CP (eds). Retina. Mosby: St Louis, 2001, 3rd edn, Vol 3, pp 2076-2099.

52 Marmor MF. New hypothesis on the pathogenesis and treatment of serous retinal detachment. Graefe's Arch Clin Exp Ophthalmol 1988; 226: 548-552. 
53 Yannuzzi LA, Freund KB, Goldbaum M et al. Polypoidal choroidal vasculopathy masquerading as central serous chorioretinopathy. Ophthalmology 2000; 107: 767-777.

54 Yannuzzi LA, Wong DWK, Scassellati Sforzolini B et al. Polypoidal choroidal vasculopathy and neovascularized age related macular degeneration. Arch Ophthalmol 1999; 117: 1503-1510.

55 Aaberg TM, Pawlowski GJ. Exudative retinal detachments following scleral buckling with cryotherapy. Am J Ophthalmol. 1972; 741: 245-251.

56 Byer NE. Clinical study of retinal breaks. Trans Am Acad Ophthalmol Otolaryngol 1967; 71: 461-473.

57 Neumann E, Hyams S, Barakai S. Conservative management of retina breaks: a follow-up study of subsequent retinal detachment. Br J Ophthalmol 1972; 56: 482-486.

58 Combs JL, Welch RB. Retinal breaks without detachment: natural history, management and long-term follow up. Trans Am Ophthalmol Soc 1982; 80: 64-97.

59 Spencer LM, Foos RY, Straatsma BR. Enclosed bays of the ora serrata. Arch Ophthalmol 1970; 83: 421-425.

60 Spencer L, Foos R, Straatsma B. Meridional folds, meridional complexes and abnormalities of the peripheral retina. Am J Ophthalmol 1970; 70: 697-714.

61 Rutnin U, Schepens C. Fundus appearance in normal eyes. II. The standard peripheral fundus and developmental variations. Am J Ophthalmol 1967; 64: 840-852.

62 Foos R, Allen R. Retinal tears and lesser lesions of the peripheral retina in autopsy eyes. Am J Ophthalmol 1967; 64: 643-655.

63 Spencer LM, Straatsma BR, Foos RY. Tractional degenerations of the peripheral retina. In: Transactions of the New Orleans Academy of Ophthalmology. Symposium on retina and retinal surgery. Mosby: St Louis, 1969, pp 103127.

64 Byer N. Cystic retinal tufts and their relationship to retinal detachment. Arch Ophthalmol 1981; 99: 1788-1790.

65 Foos R. Zonular traction tufts of the peripheral retina in cadaver eyes. Arch Ophthalmol 1969; 82: 620-632.

66 Bradford J, Wilkinson CP, Fransen S. Pseudophakic retinal detachments. The relationships between retinal tears and the time following cataract surgery at which they occur. Retina 1989; 3: 181-186.

67 Mayer E, Kurz GH. Retinal pits. A study of pathologic findings in two cases. Arch Ophthalmol 1963; 70: 640-646.

68 Parelhoff E, Wood W, Green WR. Radial perivascular lattice degeneration of the retina. Ann Ophthalmol 1980; 12: 25-32.

69 Straatsma BR, Zeegen PD, Foos RY et al. Lattice degeneration of the retina. Trans Am Acad Ophthalmol Otolaryngol 1974; 78: 87-113.

70 Straatsma BR, Allen RA. Lattice degeneration of the retina. Trans Am Acad Ophthalmol Otolaryngol 1962; 66: 600-613.

71 Byer N. Lattice degeneration of the retina. Surv Ophthalmol 1978; 23: 213-248.

72 Foos R. Postoral peripheral retinal tears. Ann Ophthalmol 1974; 6: 679-687.

73 Foos RY. Vitreous base, retinal tufts and retinal tears: pathogenic relationships. In: Pruett RC, Regan CD (eds). Retina Congress. Appleton-Century Crofts: New York, 1974, pp 259-280.
74 Davis MD. Natural history of retinal breaks without detachment. Arch Ophthalmol 1974; 92: 183-194.

75 Haimovici R, Nicholson DH. Lattice degeneration of the retina. In: Albert DM, Jakobiec FA (eds). Principles and Practice of Ophthalmology. WB Saunders: Philadelphia, 1994, Vol 2, pp 1050-1055.

76 Pecold K, Czaplicka E, Bernardczyk J. Retinoschisis vs retinal detachment-diagnosis and treatment. Klin Oczna 1993; 95: 32-34

77 Kaluzny J. Myopia and retinal detachment. Pol Med J 1970; 9: 1544-15449.

78 The Eye Disease Case-control Study Group. Risk factors for idiopathic rhegmatogenous retinal detachment. Am J Epidemiol 1993; 137: 749-757.

79 Kirker GEM, McDonald DJ. Peripheral retinal degeneration in high myopia. Canad J Ophthal 1971; 6 58-61.

80 Curtin BJ. Ocular findings and complications. In: Curtin BJ (ed). The Myopias. Basic Science and Clinical Management. Harper and Row: Philadelphia, 1985, pp 297-299.

81 Celorio JM, Pruett RC. Prevelance of lattice degeneration and its relation to axial length in severe myopia. Am J Ophthalmol 1991; 111: 20-23.

82 Grossniklaus HE, Green WR. Pathologic findings in pathologic myopia. Retina 1992; 12: 127-133.

83 Vander JF, Duker JS, Jaeger EA. Miscellaneous diseases of the fundus. In: Duane, TD (ed). Clinical

Ophthalmology. Lippincot-Raven: Philadelphia, 1997, Vol 3, pp 2-7.

84 Stein R, Pinchas A, Treister G. Prevention of retinal detachment by a circumferencial barrage prior to lens extraction in high myopic eyes. Ophthalmologica 1972; 165: 125-136.

85 Yanoff M. Prophylactic cryotherapy of retinal breaks. Ann Ophthalmol 1977; 9: 283-286.

86 Soubrane G, Coscas G, Khun D. Myopia. In: Guyer DR et al (eds). Retina-Vitreous-Macula. WB Saunders: Philadelphia, 1999, Vol 1, p 195.

87 Blankenship GW, Ibanez-Langlois S. Treatment of myopic macular hole and detachment. Intravitreal gas exchange. Ophthalmology 1987; 94: 333-336.

88 Garcia-Arumi J, Correa CA, Corcostegui B. Comparative study of different techniques of intraocular gas tamponade in the treatment of retinal detachment due to macular hole. Ophthalmologica 1990; 201: 83-91.

89 Hilding AC. Normal vitreous, its attachments and dynamics during ocular movement. Arch Ophthalmol 1954; 52: 497-514

90 Hilding AC. Alterations in the form, movement, and structure of the vitreous body in aphakic eyes. Arch Ophthalmol 1954; 52: 699-709.

91 McDonnell PJ, Patel A, Green WR. Comparison of intracapsular and extracapsular cataract surgery. Ophthalmology 1985; 92: 1208-1225.

92 Osterlin S. Macromolecular composition of the vitreous in the aphakic owl monkey eye. Exp Eye Res 1978; 26 77-84.

93 Heller MD, Straatsma BR, Foos RY. Detachment of the posterior vitreous in phakic and aphakic eyes. Mod Probl Ophthal 1972; 10: 23-36.

94 Norregaard JC, Thoning H, Anderson TF et al. Risk of retinal detachment following cataract extraction: results 
from the international cataract surgery outcomes study. Br J Ophthalmol 1996; 80: 689-693.

95 Smith PW, Stark WJ, Maumenee AE et al. Retinal detachment after extracapsular cataract extraction with posterior chamber intraocular lens. Ophthalmology 1987; 94: 495-504.

96 Tielsch JM, Legro MW, Cassard SD et al. Risk factors for retinal detachment after cataract surgery. A populationbased case-control study. Ophthalmology 1996; 103: 15371545.

97 Norton EWD, Machemer R. New approach to the treatment of selected retinal detachments secondary to vitreous loss at cataract surgery. Am J Ophthalmol 1971; 72: 705-707.

98 Balles MW. Traumatic retinopathy. In: Albert DM, Jakobiec FA (eds). Principles and Practice of Ophthalmology. WB Saunders: Philadelphia, 1994, Vol 2, pp 1029-1031.

99 Giovinazzo VJ, Yannuzzi LA, Sorenson JA et al. The ocular complications of boxing. Ophthalmology 1987; 94: 587-596.

100 Goffestein R, Burton TC. Differentiating traumatic from nontraumatic retinal detachment. Ophthalmology 1982; 89: 361-368.

101 Malbran E, Dodds R, Hulsbus R. Traumatic retinal detachment. Mod Probl Ophthal 1972; 10: 479-489.

102 Cleary PE, Ryan SJ. Experimental posterior penetrating eye injury in the rabbit. I. Method of production and natural history. Br J Ophthalmol 1979; 63: 306-311.

103 Cleary PE, Ryan SJ. Experimental posterior penetrating eye injury in the rabbit. II. Histology of wound, vitreous, and retina. Br J Ophthalmol 1979; 63: 312-321.

104 Cleary PE, Ryan SJ. Vitrectomy in penetrating eye injury. Results of a controlled trial of vitrectomy in an experimental posterior penetrating eye injury in the rhesus monkey. Arch Ophthalmol 1981; 99: 287-291.

105 Gregor Z, Ryan SJ. Complete and core vitrectomies in the treatment of experimental posterior penetrating eye injury in the rhesus monkey. I. Clinical features. Arch Ophthalmol 1983; 101: 441-445.

106 Gregor Z, Ryan SJ. Complete and core vitrectomies in the treatment of experimental posterior penetrating eye injury in the rhesus monkey. II. Histologic features. Arch Ophthalmol 1983; 101: 446-450.

107 Hsu HT, Ryan SJ. Natural history of penetrating ocular injury with retinal laceration in the monkey. Graefe's Arch Clin Exp Ophthalmol 1986; 224: 1-6.

108 Cox MS. Retinal breaks caused by blunt nonperforating trauma at the point of impact. Trans Am Ophthalmol Soc 1980; 78: 414-466.

109 Cox MS, Schepens CL, Freeman HM. Retinal detachment due to ocular contusion. Arch Ophthalmol 1966; 76: 678685.

110 Tasman W. Peripheral retinal changes following blunt trauma. Trans Am Ophthalmol Soc 1972; 70: 190-198.

111 Sellors PJH, Mooney D. Fundus changes after traumatic hyphema. Br J Ophthalmol 1973; 57: 600-607.

112 Hagler WS. Retinal dialysis: a statistical and genetic study to determine pathogenic factors. Trans Am Ophthalmol Soc 1980; 78: 686-733.

113 Dumas J. Retinal detachment following contusion of the eye. Int Ophthalmol Clin 1967; 7: 19-38.

114 Weidenthal DT, Schepens CL. Peripheral fundus changes associated with ocular contusion. Am J Ophthalmol 1966; 62: 465-477.

115 Delori F, Pomerantzeff O, Cox MS. Deformation of the globe under high-speed impact: its relation to contusion injuries. Invest Ophthalmol 1969; 8: 290-301.

116 Dugel PU, Ober RR. Posterior segment manifestations of closed-globe contusion injury. In: Ryan SJ, Wilkinson CP (eds). Retina. Mosby: St Louis, 2001, 3rd edn, Vol 3, pp 2386-2399.

117 Aaberg TM, Blair CG, Gass JHM. Macular holes. Am J Ophthalmol 1970; 365: 555-562.

118 Gass JDM. Stereoscopic Atlas of Macular Diseases: Diagnosis and Treatment. Mosby: St Louis, 1997, 4th edn, pp 744747.

119 Garcia-Arumi J, Corcostegui B, Cavero L et al. The role of vitreoretinal surgery in the treatment of postraumatic macular hole. Retina 1997; 17: 372-377.

120 Rubin JS, Glaser BM, Thompson JT et al. Vitrectomy, fluid-gas exchange and transforming growth factor-Beta2 for the treatment of traumatic macular holes. Ophthalmology 1995; 102: 1840-1845.

121 Tasman WH . Vitreoretinal dystrophy. In: Duane TD (ed). Clinical Ophthalmology. Lippincot-Raven: Philadelphia, 1997, Vol 3, p 3.

122 Yamana T, Kita M, Ozaki S et al. The process of closure of experimental retinal holes in rabbit eyes. Graefe's Arch Clin Exp Ophthalmol 2000; 238: 81-87.

123 Guerin CJ, Anderson DH, Fariss RN et al. Retinal reattachment of the primate macula. Photoreceptor recovery after short-term detachment. Invest Ophthalmol Vis Sci 1989; 30: 1708-1725.

124 Berglin L, Algvere PV, Seregard S. Photoreceptor decay over time and apoptosis in experimental retinal detachment. Graefe's Arch Clin Exp Ophthalmol 1997; 235 : 306-312.

125 Chang CJ, Lai WW, Edward DP et al. Apoptotic photoreceptor cell death after traumatic retinal detachment in humans. Arch Ophthalmol 1995; 113: 880886

126 Kroll AJ, Machemer R. Experimental retinal detachment and reattachment in the rhesus monkey. Electron microscopic comparison of rods and cones. Am J Ophthalmol 1969; 68: 58-77.

127 Machemer R, Kroll AJ. Experimental retinal detachment in the owl monkey. VII. Photoreceptor protein renewal in normal and detached retina. Am J Ophthalmol 1971; 71: 690-695.

128 Kaba F, el Baba F, Green R. Uveal neovascularization at the ora serrata and pars plana. Ann Ophthalmol 1987; 19: 85-90.

129 Matsuo N, Matsuo T, Shiragawa F et al. Photoreceptor outer segments in the aqueous humor of patients with atopic dermatitis and retinal detachment. Am J Ophthalmol 1993; 115: 21-25.

130 Lincoff $\mathrm{H}$, Kreissig I. The mechanism of the cryosurgical adhesion. IV. Electron microscopy. Am J Ophthalmol 1971; 71: 674-689.

131 Curtin VT, Fujino T, Norton EWD. Comparative histopathology of cryosurgery and photocoagulation. Observations on the advantages of cryosurgery in retinal detachment. Arch Ophthalmol 1966; 75: 674-682.

132 Campochiaro PA, Kaden IH, Vidaurri-Leal J. Cryotherapy enhances intravitreal dispersion of viable 
retinal pigment epithelial cells. Arch Ophthalmol 1985; 103: $434-436$

133 Tso MO, Wallow IH, Elgin S. Experimental photocoagulation of the human retina. Arch Ophthalmol 1977; 95: 1035-1040.

134 Wallow IH, Davis MD. Clinicopathologic correlation of Xenon arc and argon laser photocoagulation. Arch Ophthalmol 1979; 97: 2308-2315.

135 Wallow IH, Sponsel WE, Stevens TS. Clinicopathologic correlation of diode laser burns in monkeys. Arch Ophthalmol 1991; 109: 648-653.

136 Smiddy WE, Hernandez E. Histopathologic characteristics of diode lase-induced chorioretinal adhesions for experimental retinal detachment in rabbit eyes. Arch Ophthalmol 1992; 110: 1630-1633.

137 Wilson DJ, Green WR. Histopathologic study of the effect of retinal detachment surgery on 49 eyes obtained post mortem. Am J Ophthalmol 1987; 103: 167-179.

138 Barr CC. The histopathology of successful retinal reattachment. Retina 1990; 10: 189-194.

139 Boniuk M, Zimmerman LE. Pathological anatomy of complications. In: Schepens CL, Regan C (eds). Controversial Aspects of the Management of Retinal Detachment. Little Brown: Boston,1965, pp 263-311.

140 Machemer R. Experimental retinal detachment in the owl monkey. IV. The reattached retina. Am J Ophthalomol 1968; 66: 1075-1091.

141 Anderson DH, Guerin CJ, Erickson PA et al.
Morphological recovery in the reattached retina. Invest Ophthalomol Vis Sci 1986; 27: 168-183.

142 D'Hermies F, Korobelnid JF, Caputo G et al. Encapsulation of scleral buckling materials. Ophthalomology 1998; 105: 1079-1086.

143 Kreiger AE. The pars plana incision: experimental studies, pathologic observations, and clinical experience. Tran Amer Ophthalmol Soc 1991; 89: 549-621.

144 Kock FH, Kreiger AE, Spitznas M et al. Pars plana incisions of four patients: histopathology and electron microscopy. Br J Ophthalmol 1995; 79: 486-493.

145 Mietz H, Walshe R, Weidemann P et al. Histopathologic study of epiretinal proliferations after vitrectomy with daunomycin and silicone oil. Retina 1994; 14: 425-429.

146 Laroche L, Pavlakis C, Saraux H et al. Ocular findings following intravitreal silicone injection. Arch Ophthalmol 1983; 101: 1422-1425.

147 Eller AW, Friberg TR, Mah F. Migration of silicone oil into the barin: a complication of intraocular silicone oil for retinal tamponade. Am J Ophthalmol 2000; 129: 685688.

148 Doi M, Ning M, Ida $\mathrm{H}$ et al. Histopathologic retinal changes with intravitreous fluorosilicone oil in rabbit eyes. Retina 2000; 20: 532-536.

149 Elsing SH, Fekrat S, Green WR et al. Clinicopathologic findings in eyes with retained perfluoro-n-octane liquid. Ophthalmology 2001; 108: 45-48. 